\title{
A NEW ESTIMATE FOR BRAZILIAN VERTICAL DATA OFFSET BASED ON GLOBAL GEOPOTENTIAL MODELS AND HEIGHT DETERMINATIONS THROUGH RELATIVE APPROACH
}

\author{
Uma nova estimativa para o afastamento dos Data Verticais Brasileiros \\ baseada em modelos globais do geopotencial e determinações altimétricas \\ por abordagem relativa
}

Eurico Nicacio ${ }^{1}$ - ORCID: 0000-0001-6949-8757

Regiane Dalazoana ${ }^{1}$ - ORCID: 0000-0001-5468-0679

${ }^{1}$ Universidade Federal do Paraná, Setor de Ciências da Terra, Departamento de Geomática, Programa de Pós-Graduação em Ciências Geodésicas, Curitiba - Paraná, Brasil.

E-mail: euriconicaciojr@gmail.com; regiane@ufpr.br

Received in January $18^{\text {th }}, 2018$

Accepted in May 06 ${ }^{\text {th }}, 2018$

\begin{abstract}
:
This paper aims to present a new estimate for the vertical offset between both Brazilian vertical data: DVB-I, in Imbituba-SC, and DVB-S, in Santana-AP. Brazilian Fundamental Altimetric Network (BFAN) currently has over 69000 stations with known normal-orthometric heights; 472 of these stations are connected to a tide gauge located in Santana-AP, at the North portion of Brazil, and the other ones are connected to a tide gauge located in Imbituba-SC, at the South portion of Brazil and considered Brazilian's main vertical reference. The vertical offset estimate is based on comparisons between reference and calculated normal-orthometric heights from values obtained arising of discrete GNSS observations on BFAN benchmarks, normal-geoid heights calculated from GGM XGM2016, which has proven to better model this variable in the region, and through a relative approach for heights determination, which has also proven to be the best way to handling the appropriate variables. As a result, a vertical offset of $1.32 \mathrm{~m} \pm 0.07 \mathrm{~m}$ was obtained, which is coherent to previous studies performed in the same intent. This study up-comes as a new validation of the employed methodology itself, by achieving satisfactory results through independent manipulation even with low quality of input data for the region.
\end{abstract}

Keywords: Vertical data offset; Global geopotential models; Relative approach; Brazilian Fundamental Altimetric Network. 


\section{Resumo:}

O propósito deste trabalho é apresentar uma nova estimativa para o afastamento vertical entre ambos os data verticais brasileiros: DVB-I, em Imbituba-SC, e DVB-S, em Santana-AP. A Rede Altimétrica Fundamental Brasileira (RAFB) atualmente conta com mais de 69000 estações com altitudes normais-ortométricas conhecidas; 472 destas estações estão conectadas ao marégrafo localizado em Santana-AP, na porção Norte do Brasil, e as demais estão conectadas ao marégrafo localizado em Imbituba-SC, na região Sul do Brasil e principal referência vertical brasileira. A estimativa do afastamento é baseada em comparações entre altitudes normais-ortométricas de referência e calculadas por valores obtidos através de observações GNSS discretas em referências de nível da RAFB, altitudes normais-geoidais calculadas do MGG XGM2016, o qual comprovadamente melhor modela esta variável na região, e através de uma abordagem relativa para determinações altimétricas, a qual também é, comprovadamente, a melhor forma para manipular as variáveis cabíveis. Como resultado, um afastamento vertical de $1.32 \mathrm{~m} \pm 0.07 \mathrm{~m}$ foi obtido, o qual é coerente com estudos anteriores realizados com mesmo intuito. Este estudo surge como uma nova validação da metodologia empregada em si, alcançando resultados satisfatórios através de manipulação independente mesmo com a baixa qualidade dos dados de entrada na região.

Palavras-chave: Afastamento entre data verticais; Modelos globais do geopotencial; Abordagem relativa; Rede Altimétrica Fundamental Brasileira.

\section{Introduction}

Mueller (1985) defines that the purpose of a reference frame is to provide the means to materialize a reference system so that it can be used for the quantitative description of positions and motions on the earth (terrestrial frames), or of celestial bodies, including the earth, in space (celestial frames). For the circumstance of vertical reference systems, the networks associated with them are exactly materializations or physical realizations of their vertical coordinates.

For the particular case of Brazilian Fundamental Altimetric Network (BFAN), one of the networks that integrate the Brazilian Geodetic System (BGS) and under responsibility of Brazilian Institute of Geography and Statistics (IBGE), these realizations are provided in terms of benchmarks distributed heterogeneously over the entire Brazilian territory and linked to a national reference system. These benchmarks carry out normal-orthometric heights information, which are heights arising from leveling operations, only corrected from the non-parallelism of gravity field equipotential surfaces (Luz, 2008). Its establishment has begun in 1945, starting over from Brazilian South region and spreading to North and Northeast regions later. Currently, there are over 69000 stations, which distribution and leveling epoch are shown in figure 1. In such figure, stations are presented pointwisely, but they seem as leveling lines due to their large amount. Further information about BFAN/BGS can be viewed in Luz (2008) and Nicacio (2017).

In spite of several issues concerning BFAN, such as: a lack of consideration of vertical movements for benchmarks established in different epochs; the existence of network benchmarks which heights were not adjusted with the whole network adjustment and the consequent lack of reliability on their accuracy (namely, the "branch" stations); the network evident heterogeneity; among others; one problem is even more worrisome: currently, there are two vertical data, located in different Brazilian regions and that are not physically connected. These data are: the 
Brazilian Vertical Datum in Imbituba-SC (in Portuguese, "Datum Vertical Brasileiro em Imbituba" DVB-I) and the Brazilian Vertical Datum in Santana-AP (in Portuguese, "Datum Vertical Brasileiro em Santana" - DVB-S).
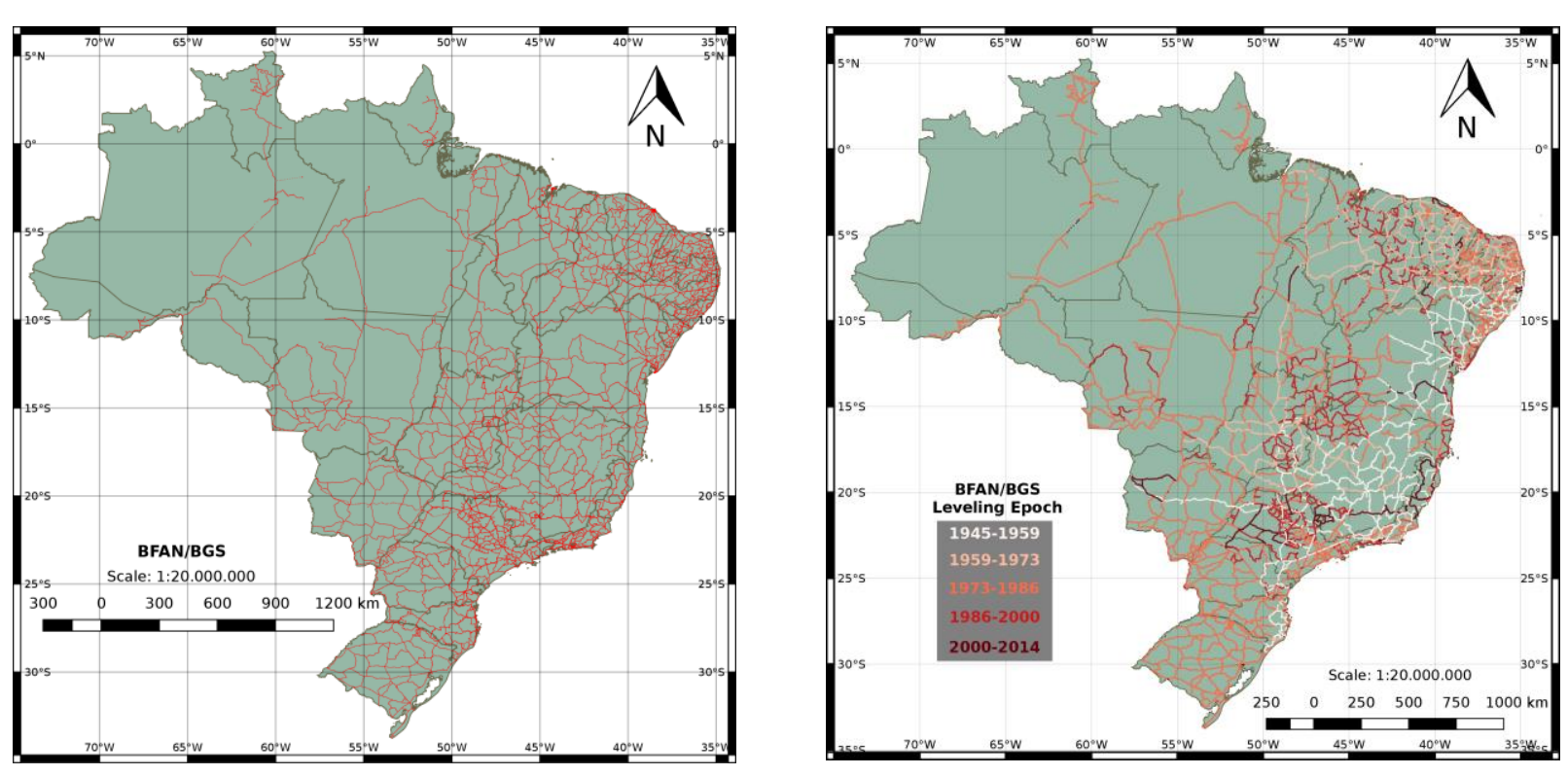

Figure 1: BFAN stations distribution (left) and leveling epoch (right) in Brazil; boundaries and additional information are omitted.

From all of the benchmarks on BFAN, only 472 of them have their normal-orthometric heights referred to a tide gauge placed at DVB-S, as shown in figure 2 . The other remaining stations, which present in a larger number, have their normal-orthometric heights referred to a tide gauge placed at DVB-I. The lack of physical connection occurs due to operational issues for river crossing techniques and logistics issues concerning the Brazilian Amazon rain forest.

Since there are variations in the sea level for every coast location, vertical references based on tide gauge readings may vary severely even considering a $30^{\circ}$ difference in latitude for both Brazilian vertical data. So, a number of papers have already been developed proposing analytical methods for connecting or even for estimating the vertical offset between these references, such as De Freitas et al. (2016), Moreira (2015), Castro and De Freitas (2014) and Castro (2011), each one of them using different techniques and achieving results as displayed in table 1 . Further details on each approach are omitted from the present study for brevity reasons. 


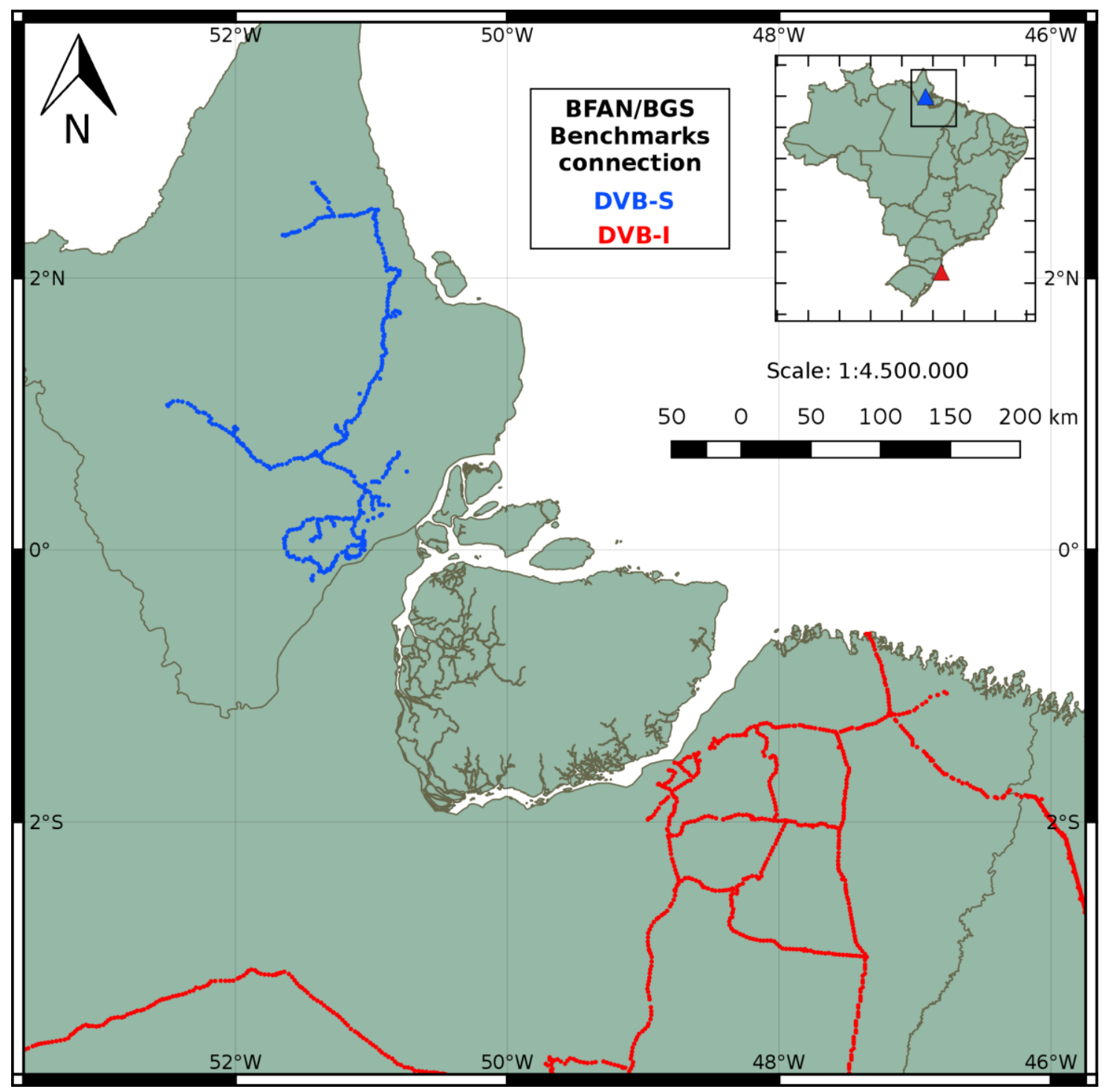

Figure 2: BFAN benchmarks referred to DVB-I (red) and DVB-S (blue).

Note: The upward map indicates the tide gauges location.

Table 1: Authors and offset values determined between DVB-I and DVB-S.

\begin{tabular}{c|c}
\hline Authors & Offset (m) \\
\hline De Freitas et al. (2016) & $1.415 \mathrm{~m} \pm 0.12 \mathrm{~m}$ \\
\hline Moreira (2015) & $1.300 \mathrm{~m} \pm 0.11 \mathrm{~m}$ \\
\hline Castro and De Freitas (2014) & $1.301 \mathrm{~m}$ up to $1.420 \mathrm{~m}$ \\
\hline Castro (2011) & $1.320 \mathrm{~m}$ or $1.430 \mathrm{~m}$ \\
\hline
\end{tabular}


However, in this paper, we intend to expose the methods applied by Nicacio (2017) for providing a new estimate for this offset, based on comparisons between known normal-orthometric heights and values obtained from discrete GNSS observations on specific BFAN benchmarks, normal-geoid heights calculated from GGM XGM2016, which has been proven to better model this variable in the region (Nicacio, 2017), and through a relative approach for heights determination, which has also been proven to be the best way to handling appropriate variables (Nicacio, 2017).

\section{Methods}

\subsection{Terrestrial data}

As already stated in the previous item, in order to perform the proposed estimate, terrestrial data were selected according to the information needed, which are reference normal-orthometric heights $\left(H^{\text {NOrt }}\right)$ and ellipsoidal heights $(h)$. The first ones, as already discussed, are related to benchmarks of BFAN and are the closest approach to heights with physical meaning; the last ones are related to previously observed points with GPS/GNSS techniques and concern to the Brazilian SAT-GPS Network. This last network is also provided and maintained by IBGE, and both of them are freely accessible to all the community (IBGE, 2017), together with further information on its composition.

So, benchmarks from BFAN which intersect SAT-GPS Network stations in the study area were selected, since they gather the needed information - normal-orthometric heights $\left(H^{N O r t}\right)$ and ellipsoidal heights $(h)$ - as explained more fully on section 2.3 of the present paper. Thus, 19 stations distributed in the surrounding of DVB-S were pointed out, as displayed in figure 3 , being henceforth named GNSS/BM stations. It is important to notice that 18 of these GNSS/BM stations are referenced to DVB-S, being one of them highlighted with different color, and one is referenced to DVB-I, being especially important for the vertical data offset estimation, due to reasons also explored on section 2.4. Their naming is according to national and institutional pattern.

Yet in the referred figure, it is possible to verify the significant distance between the GNSS/BM stations referenced to DVB-S and the station linked to DVB-I. This was adopted in order to preserve the signaled station, which carries the most reliable and accurate altimetric information in the aimed surroundings. In addition, the distance is not an issue, since Nicacio (2017) pointed out that there is no relation between stations distance and quality of the result of altimetric determinations when employing similar methodology and, mainly, a relative approach. 


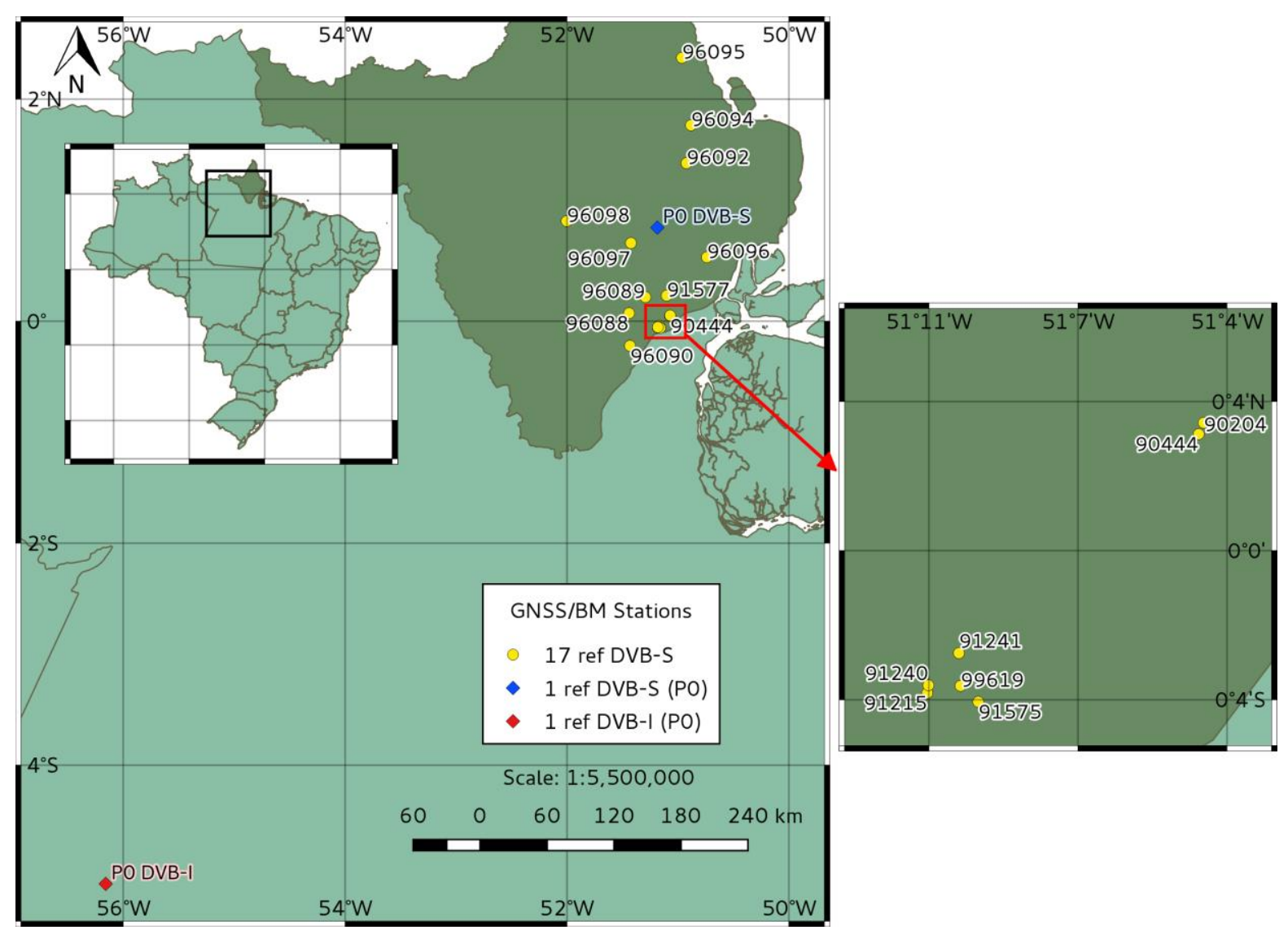

Figure 3: GNSS/BM stations used in the present paper.

\subsection{GGM data}

To sum up, Global Geopotential Models (GGMs) consist of sets of numeric values for some parameters, the associated error statistics and a collection of mathematic expressions, numeric values and particular algorithms, as well as the providential application of these data when developing the geopotential in spherical harmonics, as shown in equation 1 (Barthelmes and Köhler, 2016). In this equation, $a$ is the major semiaxis of the ellipsoid associated to the model, $\omega$ is the rotation speed of the model, $C_{n m}$ and $S_{n m}$ are the series development coefficients, $G M$ is the geocentric gravitational constant associated to the model, $(r, \varphi, \lambda)$ are the geocentric coordinates, as follows: $r$ is the distance of the calculation point to the adopted model geocenter, $\varphi$ is the calculation point geodetic latitude and $\lambda$ is the calculation point geodetic longitude, and $P_{n m}$ represent the associated Legendre functions with degree $n$ and order $m$.

$$
\begin{gathered}
W(r, \varphi, \lambda)=\frac{G M}{r}\left[1+\sum_{n=2}^{\infty} \sum_{m=0}^{n}\left(\frac{a}{r}\right)^{n}\left(C_{n m} \cos (m \lambda)+S_{n m} \sin (m \lambda)\right) P_{n m}(\sin (\varphi))\right]+ \\
+\frac{1}{3} \omega^{2} r^{2}\left[1-P_{20}(\sin (\varphi))\right]
\end{gathered}
$$

Nowadays, due to the complexity of obtaining and maintaining these models, as well as the need to control and standardize all related variables, their management is performed globally by ICGEM - International Centre for Global Earth Models. Its database sums 168 static models, from which 
we highlight in this paper the combined models, which gather gravity information upcoming from satellite orbit observations, terrestrial gravimetry and altimetry (both digital elevation model data, for land and coastal regions, and satellite altimetry, for oceans) in order to solve the geopotential modelling (Seeber, 2003).

In this sense, and according to previous results achieved, such as by Nicacio (2017) and Nicacio and Dalazoana (2017), the optimal configuration of combined GGMs for modeling normal-geoid heights and consequently normal-orthometric heights in the desired area, as explained in item 2.3, is achieved with GGM XGM2016 (Pail et al., 2016), through geopotential functional height anomaly and developed up to degree 719. This is the configuration used in every GGM manipulation for this paper.

The acquirement of GGM extracts was performed pointwisely, in each of the GNSS/BM stations, in order to preserve characteristics and precision of the model. With such approach, further losses with the application of interpolation methods were avoided (Nicacio and Dalazoana, 2016). For such task, it was used the standalone application SPGG v2.0 (Nicacio, 2016), which provide pointwise extracts of GGMs according to functionals and defining characteristics inserted by the user, through direct interaction with ICGEM web service. A visualization of its interface is prompted in figure 4. The GGM extracts were acquired in GRS80 reference system, including zerodegree term and in zero tide system.

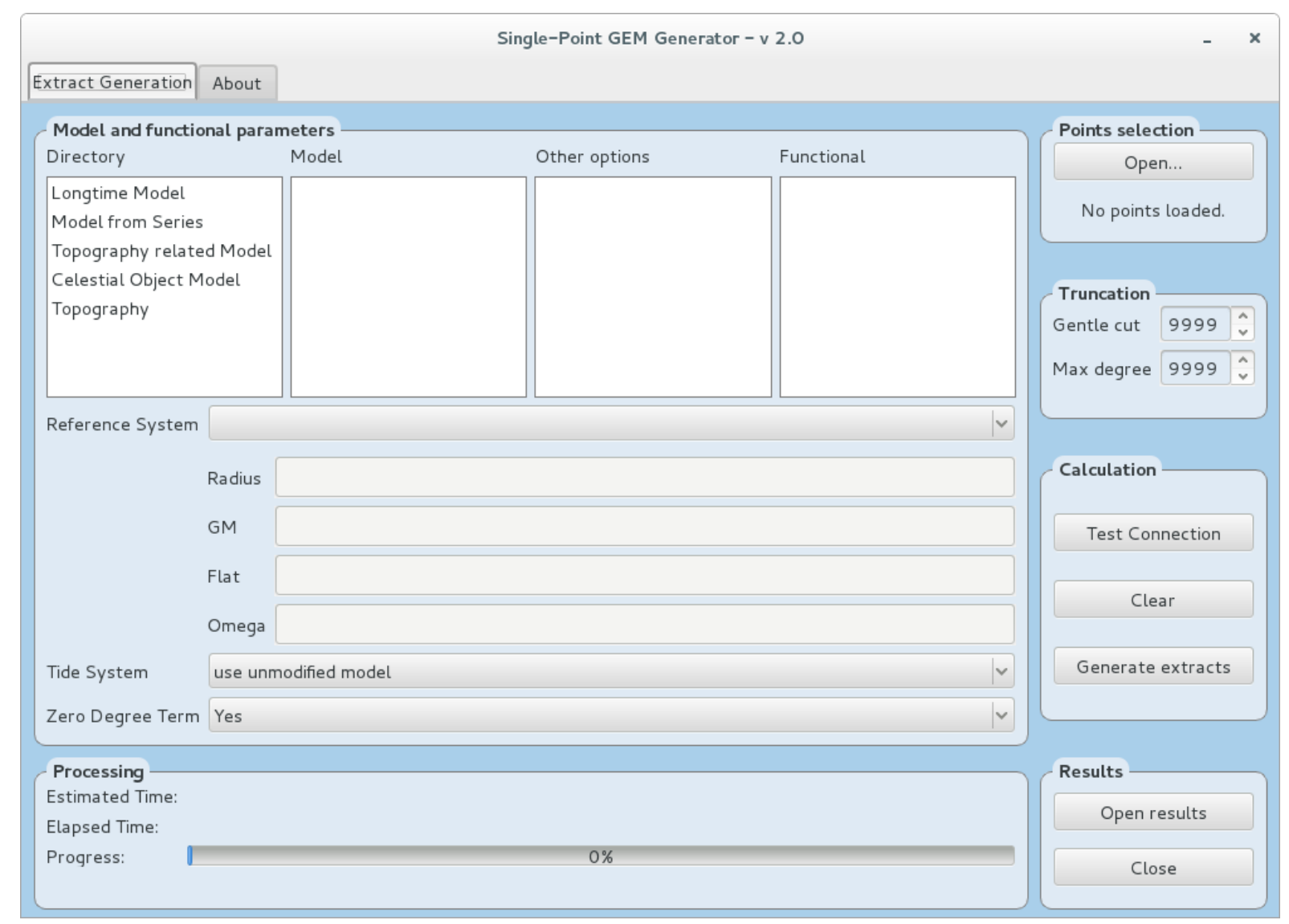

Figure 4: Standalone application SPGG v2.0, employed to obtain GGM data. 


\subsection{Normal-orthometric heights modeling}

Since, as already stated, normal-orthometric heights behavior do not present a complete physical meaning, they are not referred or related to a classical reference surface, such as the geoid or the quasi-geoid. Thus, a regular mathematical equation that relates ellipsoidal heights $(h)$ and orthometric heights $\left(H^{\text {Ort }}\right)$, for example, by means of geoid heights $\mathrm{N}\left(h=H^{\text {ort }}+N\right)$ may not be freely used as if BFAN benchmarks heights were, in fact, orthometric heights. Consequently, Ferreira et al. (2013) describe, still, the dependency of ellipsoidal heights $(h)$ and normalorthometric heights ( $H^{\text {NOrt }}$ ) to the models of equation 2 , in which $\eta$ is by them named normalgeoid heights, as an analogy to normal-orthometric heights and the naming used in this paper.

$$
H^{N O r t}=h-\eta
$$

Since normal-geoid heights are not geopotential functionals, they may be better modeled by geoid heights $N$ themselves or by height anomalies $\zeta$, depending on the study area. Nicacio (2017) and Nicacio and Dalazoana (2017) verified that, in the surroundings of the present study area, normalgeoid heights are better modeled by height anomalies, which is the reason why they integrate the already mentioned optimal configuration.

However, in order to mitigate additive errors inherent to the processing system and to the obtaintion method of the GGMs, Nicacio (2017), Sánchez (2016) and Featherstone (2001) propose the usage of the relative method instead of the absolute one described in equation 2 , which is based, in the context of this work, on the use of an origin point $P_{0}$ as a reference, with known normal-orthometric height $H_{0}$, ellipsoidal height $h_{0}$ and normal-geoid height $\eta_{0}$ and through the mathematical approach presented in equation 3 . The described formulation has already proved as being more efficient when handling GGMs in previous studies by the mentioned authors and was described by Sánchez (2016) as the most adequate manner under the optics of vertical reference systems determination, being therefore adopted in the present paper.

$$
\left\{\begin{array}{l}
H_{0}^{N O r t}=h_{0}-\eta_{0}^{G G M}=h_{0}-\eta_{0}^{\text {real }}+\varepsilon \\
H_{P}^{N O r t}=h_{P}-\eta_{P}^{G G M}=h_{P}-\eta_{P}^{\text {real }}+\varepsilon
\end{array} \rightarrow H_{P}^{N \text { Ort }}=H_{0}^{\text {NOrt }}+h_{P}-h_{0}-\eta_{P}+\eta_{0}\right.
$$

It is important to remark that, since the concerning variables are acquired according to different permanent tide systems, it was necessary to perform their compatibilization, as formulated by Ekman (1989), Mäkinen and Ihde (2006) and Tenzer et al. (2011). Further information on this topic can be verified in the mentioned references and in Nicacio (2017).

\subsection{Strategy for estimating the vertical offset}

In the context of this paper, we aim to perform a metric estimate for the offset between both the vertical data. As signaled by Ferreira (2011), any inference carried on such attempt must take under consideration physical factors, not only mathematical ones, on the heights to them referred. 
We considered, though, that the GGM employed is the physical artifice used to give physical meaning to this estimate, since it is the physical auxiliary used for densification of normalorthometric heights, relating two quantities that are in different spaces - the normal-orthometric heights, in the space of the normal gravity potential (Ferreira, 2011), and the GGM, as an expansion of the geopotential in spherical harmonics, in the geopotential space (Barthelmes, 2013). The path taken by this paper, approaches to what Moritz (1980 apud Ferreira, 2011) defines as operational approach, basing the predictions on observations taken over the terrestrial surface.

That said, consider the existence of the 18 GNSS/BM stations which normal-orthometric heights are referred to DVB-S. Being $P_{i}$ one of these points, consider its altimetric determination through the relative approach from the one remaining GNSS/BM station, namely point $P_{0}$, which normalorthometric height is referred to DVB-I. For this scenario, figure 5 can be obtained by simplifying the reference surfaces, altimetric denominations and definitions, aiming at their better understanding, as well as exaggerating the dimensions for the comprehensiveness of all variables and features of interest.

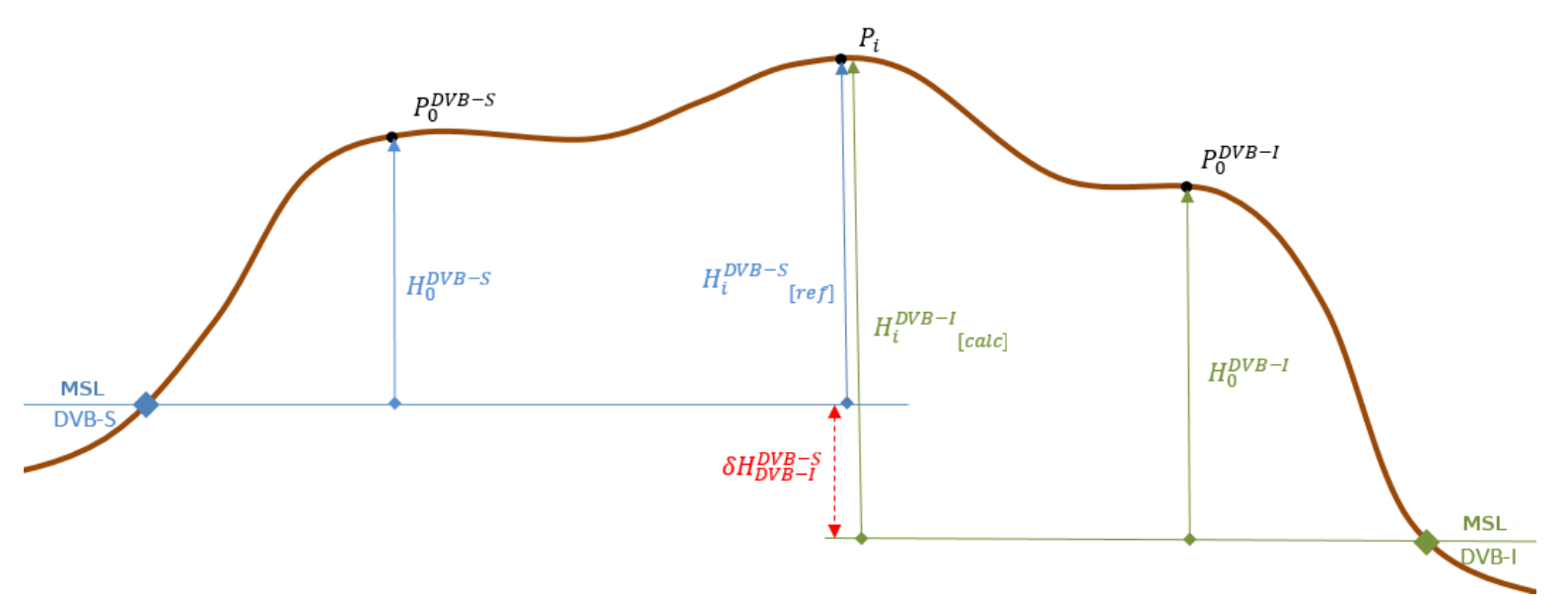

Figure 5: Strategy for estimating the vertical offset between DVB-S and DVB-I.

In the figure displayed, one can observe the existence of two points $P_{0}$, each of which has known normal-orthometric height and refers to one of the Brazilian vertical data: point $P_{0}^{D V B-S}$ is one of the $18 \mathrm{GNSS} / \mathrm{BM}$ stations mentioned above and linked to DVB-S; the point $P_{0}^{D V B-I}$ is the other GNSS/BM stations referred to the DVB-I. Origin remarks of both data were defined by large term analysis of mean sea level (MSL) in each point. Both of these stations are highlighted in figure 3, respectively as blue and red diamonds. For the procedures adopted herein, it is considered that $P_{0}^{D V B-I}$ is the GNSS/BM station named 93996 of the SAT-GPS network, as well as $P_{0}^{D V B-S}$ is the GNSS/BM station named 96091 of the SAT-GPS network - for homogeneity assumptions, it is the closest station to the center of the convex hull containing the 18 interest stations (Nicacio, 2017).

Still from figure 5, let $P_{i}$ be another GNSS/BM station referred to DVB-S, which normal-orthometric height referred to this datum is known $\left(H_{i}^{D V B-S}{ }_{[r e f]}\right)$. If this knowledge is initially ignored, it is possible to calculate $P_{i}$ normal-orthometric height referred to DVB-I, by means of equation 3 and having as origin point $P_{0}^{D V B-I}$, obtaining though its normal-orthometric height referred to DVB-I $\left(H_{i}^{D V B-I}{ }_{[\text {calc }]}\right)$.

Theoretically, the difference between the reference height, linked to one datum, and calculated one, linked to the other datum, would be equal to the vertical offset between both $\left(\delta H_{D V B-I}^{D V B-S}\right)$. 
However, given the approximations and simplifications carried out, as well as the need to confirm consistency in the existing altimetric information in each station used, it is considered that the aimed offset is given by the average between the discrepancies obtained for each station that are proven to be reliable, i.e. which are well modeled by the optimal configuration in the area, considering the reference and calculated heights, as regulated in equation 4 , where $k<18$ GNSS/BM stations have coherent behavior according to the already verified optimal configuration in the area.

$$
\left\{\begin{array}{l}
\delta H_{1}=H_{1}^{D V B-S}{ }_{[\text {ref }]}-H_{1}^{D V B-I}{ }^{[\text {calc }]} \\
\delta H_{2}=H_{2}^{D V B-S}{ }_{[\text {ref }]}-H_{2}^{D V B-I}{ }^{[\text {calc }]} \rightarrow \delta H_{D V B-I}^{D V B-S}=\frac{1}{n} \sum_{i=1}^{k} \delta H_{i} \\
\delta H_{k}=H_{k}^{D V B-S}{ }_{[\text {ref }]}-H_{k}^{D V B-I}{ }_{[\text {calc }]}
\end{array}\right.
$$

Thus, the first step to perform the estimation is verifying which of the 18 GNSS/BM stations connected to DVB-S are reliable and coherent in terms of altimetric information by modeling their normal-orthometric heights through the usage of the equation 3 , adopting $P_{0}^{D V B-S}$ as the origin point and using optimal configuration already stated by Nicacio (2017) and Nicacio and Dalazoana (2017) for normal-geoid heights: GGM XGM2016, functional height anomaly and degree 719. After the elimination of possible outliers, once again perform such calculation through usage of the equation 3, adopting now $P_{0}^{D V B-I}$ as the origin point and using the same optimal configuration. For each point, as shown in equation 4 , its individual height discrepancy $\delta H$ is determined and, finally, the vertical offset $\delta H_{D V B-I}^{D V B-S}$ is estimated by their average value.

\section{Results and discussion}

\subsection{Identification of outliers among GNSS/BM stations referred to DVB-S}

Consider the existence of a metric factor named $\theta_{i}$ for every studied station, defined as being the absolute discrepancy between an absolute reference normal-orthometric height value for that station $\left(H_{i}^{N O r t}{ }_{r e f}\right)$ and an absolute calculated normal-orthometric height value for the same station $\left(H_{i}^{\text {Nort }}{ }_{\text {calc }}\right)$, by means of the displayed in equation 3 and considering the existence of a single vertical datum. For instance, for every station $i$ linked to DVB-S, equation 5 is valid.

$$
\theta_{i}=|| H_{i}^{N O r t}{ }_{\text {ref }}|-| H_{i}^{N O r t}{ }_{\text {calc }}||
$$

The analysis of such factor in GNSS/BM stations height determination in the surroundings of DVB$S$ and to it referred allows to identify possible outliers, i.e. stations with low quality or reliability of altimetric information. In this sense, figure 6 indicates a histogram of these $\theta$ factors occurrence in DVB-S surroundings and an individual analysis per interest station. 

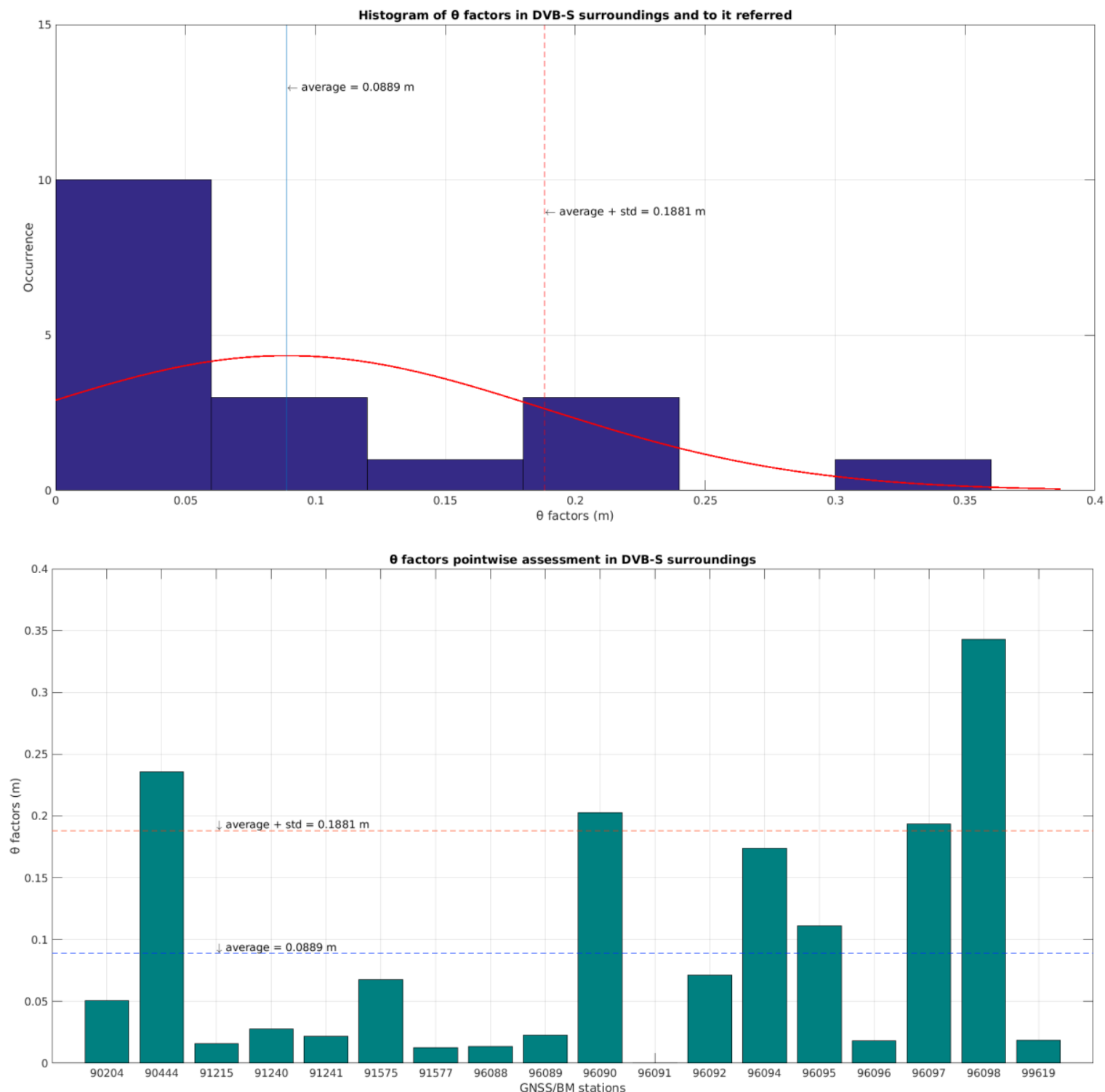

Figure 6: Histogram of $\theta$ factors in DVB-S surroundings and to it referred (top) and $\theta$ factors individual assessment per station in same conditions (bottom).

Adopting a criterion of average plus one standard deviation for identification and elimination of outliers (Nicacio, 2017), and aided by visual analysis of figure 6 , it is possible to verify the existence of 4 GNSS/BM stations which behavior was not coherent to the others, being their $\theta$ factors above the maximum established limit, namely: GNSS/BM stations 90444, 96090, 96097 and 96098. Notice that this agreed criterion, as explained by the cited author, may seem too strict, but it is under plenty necessity considering, once again, possible incorrectness in original altimetric determinations and consequent lack of reliability for such information in Brazilian North region.

Since the signaled 4 stations are not plenty in reliability concerning their altimetric information, they were considered as outliers and timely removed from the original set of stations. New statistics of the $\theta$ factors for the 14 remaining stations were calculated and are therefore displayed in figure 7 and summarized in table 2. 

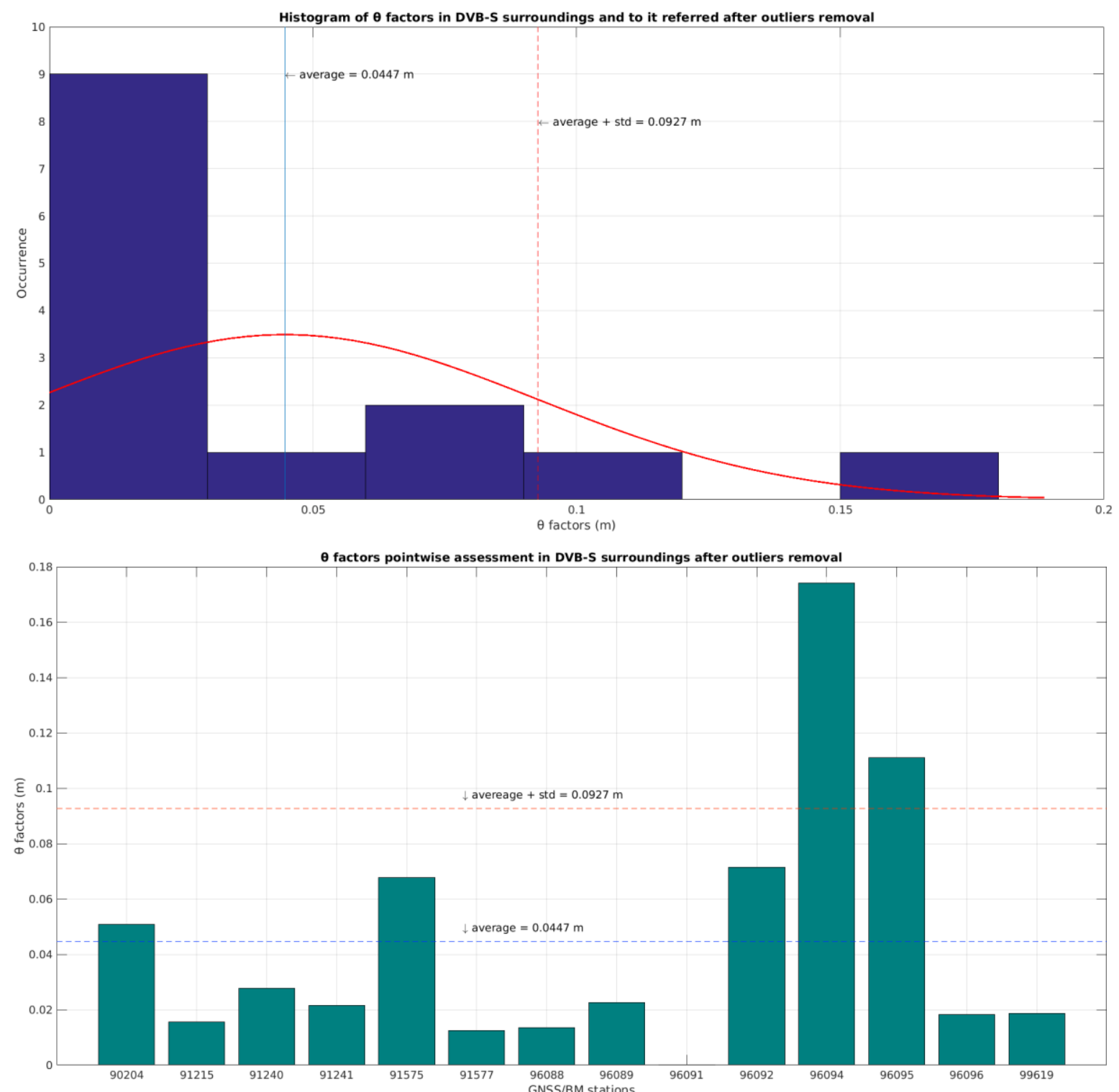

Figure 7: Histogram of $\theta$ factors in DVB-S surroundings and to it referred (top) and $\theta$ factors individual assessment per station in same conditions (bottom), both after outliers removal.

Table 2: $\boldsymbol{\theta}$ factor statistics assessment in DVB-S surroundings after outliers removal.

\begin{tabular}{c|c|c|c}
\hline & Discrepancy $(\mathrm{m})$ & Variance $\left(\mathrm{m}^{2}\right)$ & Standard deviation $(\mathrm{m})$ \\
\hline Maximum & 0.1740 & & 0.0480 \\
\hline Average & 0.0447 & 0.0021 & \\
\hline Minimum & 0.0012 & & \\
\hline
\end{tabular}

Notice that, under new conditions and after outliers elimination, there are still two stations which behavior did not follow the pattern dictated by the other stations. However, it was not carried out a new outliers elimination in order to preserve such altimetric data and to avoid the occurrence of indefinite amount of stations elimination, which could be detrimental to the proposed estimate. 
Though, the improvement imposed by outliers removal, decreasing average discrepancy in half (from $0.0889 \mathrm{~m}$ in the original set to $0.0447 \mathrm{~m}$ in the final set) is outstanding and, surely, comes as a key step for the vertical offset estimation.

\subsection{Vertical offset estimation between DVB-S and DVB-I}

After proper analysis of stations behavior, identification and removal of outliers, the next step was performing once again the altimetric determination, through usage of the same equation 3 , adopting now $P_{0}^{D V B-I}$ as the origin point and using the same optimal configuration. After this calculation, every station had an original reference normal-orthometric height referred to DVB-S $\left(H_{i}^{D V B-S}{ }_{[\text {ref }]}\right)$ and a new calculated normal-orthometric height referred to DVB-I $\left(H_{i}^{D V B-I}{ }_{[\text {calc }]}\right)$. For each station, it was calculated its individual height discrepancy $\delta H$, and for the whole set the estimate to the vertical offset between both $\left(\delta H_{D V B-I}^{D V B-S}\right)$, both of them accordingly to equation 4 . These results are displayed in table 3.

Table 3: Vertical offset estimation between DVB-I and DVB-S.

\begin{tabular}{|c|c|c|c|}
\hline GNSS/BM station & $\begin{array}{l}\text { Reference height (m) } \\
\text { [DVB-S] }\end{array}$ & $\begin{array}{c}\text { Calculate height }(\mathrm{m}) \\
\text { [DVB-I] }\end{array}$ & Discrepancy (m) \\
\hline 90204 & 16.4758 & 17.8419 & 1.3661 \\
\hline 91215 & 7.5068 & 8.8378 & 1.3310 \\
\hline 91240 & 8.5313 & 9.8744 & 1.3431 \\
\hline 91241 & 12.8364 & 14.1733 & 1.3369 \\
\hline 91575 & 5.3775 & 6.7605 & 1.3830 \\
\hline 91577 & 28.3276 & 29.6553 & 1.3277 \\
\hline 96088 & 3.8474 & 5.1763 & 1.3289 \\
\hline 96089 & 31.2162 & 32.5541 & 1.3379 \\
\hline 96091 & 53.1113 & 54.4266 & 1.3153 \\
\hline 96092 & 29.2457 & 30.6324 & 1.3867 \\
\hline 96094 & 15.9062 & 17.0475 & 1.1413 \\
\hline 96095 & 17.3906 & 18.5948 & 1.2042 \\
\hline 96096 & 14.3393 & 15.6364 & 1.2971 \\
\hline 99619 & 8.8578 & 10.1917 & 1.3339 \\
\hline \multicolumn{3}{|c|}{ Vertical offset estimate between DVB-I and DVB-S $(\mathrm{m})$ : } & 1.3166 \\
\hline
\end{tabular}


Thus, through the results presented in table 3 , it is possible to verify that the vertical offset estimation between DVB-I and DVB-S is of the order of $1.3166 \mathrm{~m} \approx 1.32 \mathrm{~m}$, being DVB-I located below DVB-S. The data standard deviation is $0.667 \mathrm{~m} \approx 0.07 \mathrm{~m}$. Still looking at the table, it is possible to verify that both stations cited in item 3.1 - namely GNSS/BM stations 96094 and 96095 - which remained with abnormal behavior even after outliers removal produced individual discrepancy incoherent when related to the other stations. If these stations were removed, the vertical offset estimation would be of the order of $1.34 \mathrm{~m} \pm 0.03 \mathrm{~m}$.

The results achieved are very consistent with those presented in table 1, being especially close to the determinations made by Castro (2011), Castro and De Freitas (2014) and Moreira (2015). The discrepancy in relation to the results presented by De Freitas et al. (2016) may be related to the fact that those authors used the absolute method and a combination of GGMs, rather than the relative method and the optimal configuration; in addition, it is emphasized that the value now found is less than a standard deviation of difference in relation to the value obtained by those authors, being an acceptable discrepancy.

Finally, table 4 is a complete version of table 1 , including the present estimation calculated.

Table 4: Complete version of authors and offset values determined between DVB-I and DVB-S.

\begin{tabular}{c|c}
\hline Authors & Offset $(\mathrm{m})$ \\
\hline Present authors & $1.320 \mathrm{~m} \pm 0.07 \mathrm{~m}$ \\
\hline De Freitas et al. (2016) & $1.415 \mathrm{~m} \pm 0.12 \mathrm{~m}$ \\
\hline Moreira (2015) & $1.300 \mathrm{~m} \pm 0.11 \mathrm{~m}$ \\
\hline Castro and De Freitas (2014) & $1.301 \mathrm{~m}$ up to $1.420 \mathrm{~m}$ \\
\hline Castro (2011) & $1.320 \mathrm{~m}$ or $1.430 \mathrm{~m}$ \\
\hline
\end{tabular}

\section{Conclusions and outlook}

A new estimate for the vertical offset between both Brazilian vertical data - DVB-I, in ImbitubaSC, and DVB-S, in Santana-AP - was calculated. Such estimation is necessary since Brazilian Fundamental Altimetric Network (BFAN) currently has stations connected to a tide gauge located in Santana-AP, at the North portion of Brazil, and the others ones connected to a tide gauge located in Imbituba-SC, at the South portion of Brazil and considered Brazilian's main vertical reference. Up to the moment of elaboration of this paper, there is no physical connection between these vertical data and, despise past studies have already proposed connection strategies, benchmarks normal-orthometric heights are provided as linked to the reference datum.

The vertical offset estimate performed was based on comparisons between reference and calculated normal-orthometric heights from values obtained from discrete GNSS observations on BFAN benchmarks, normal-geoid heights calculated from GGM XGM2016, which has proven to better model this variable in the region (Nicacio and Dalazoana, 2017), and through a relative approach for heights determination, which has also been proven to be the best way to handling 
appropriate variables (Nicacio, 2017). Such procedure was accompanied by statistical analysis and outliers identification and elimination tasks, in order to provide the best estimate possible, even with questionable reliability of height information in some locations.

As a result, a vertical offset of $1.32 \mathrm{~m} \pm 0.07 \mathrm{~m}$ was calculated, which is coherent to previous studies performed in the same intent. Minor differences between this and other already established estimates are of the same order of its own standard deviation and plenty justifiable by different procedures adopted by the other authors in order to produce similar result.

To sum up, this study up-comes as a new validation of the employed methodology itself, by achieving coherent results through a totally independent technique relatively to previous papers, proving itself satisfactory even with low quality of input data for the region.

\section{ACKNOWLEDGEMENT}

The authors would like to thank Prof. Dr. Silvio Rogério Correia de Freitas, president of SIRGASGTIII and professor at the Federal University of Paraná, for the constant support to align the present paper to SIRGAS current applicable assumptions.

\section{REFERENCES}

Barthelmes, F. 2013. Definition of Functionals of the Geopotential and Their Calculation from Spherical Harmonic Models. Scientific Technical Report STR09/02. Helmoholtz-Zentrum Potsdam, GFZ Germanz Research Centre for Geosciences.

Barthelmes, F. and Köhler, W. 2016. International Centre for Global Earth Models (ICGEM). In: H. Drewes et al., ed. The Geodesists Handbook 2016, Journal of Geodesy, 90(10), pp. 907-1205, doi: 10.1007/s00190-016-0948-z

Castro, H. D. M. 2011. Proposta de alternativas para conexão dos Data Verticais Brasileiros de Imbituba e Santana. MSc. Universidade Federal do Paraná.

Castro, H. D. M. and De Freitas, S. R. C. 2014. Strategies for Connecting Imbituba and Santana Brazilian Datums Based on Satellite Gravimetry and Residual Terrain Model. In: P. W. C. Rizos (Ed.), Earth on the Edge: Science for a Sustainable Planet (Vol. 139, pp. 543-550). Berlin: Springer.

De Freitas, S. R. C. et al. 2016. Connection of the two segments of the Brazilian Vertical Reference Network. In: 1st Joint Commission 2 and International Symposium on Gravity, Geoid and Height Systems 2016 (GGHS 2016). Thessaloniki, Greece, 19-23 September 2016.

Ekman, M. 1989. Impacts of Geodynamic Phenomena on Systems for Height and Gravity. Bulletin Géodésique, 63(3), 281-296. doi: 10.1007/BF02520477

Featherstone, W. E. 2001. Absolute and relative testing of gravimetric geoid models using Global Positioning System and orthometric height data. Computers \& Geosciences, 27(7), 807-814. doi: 10.1016/S0098-3004(00)00169-2 
Ferreira, V. G. 2011. Solução do tipo Brovar para o Segundo Problema de Valor de Contorno da Geodésia com vistas à modernização de sistemas de altitudes. PhD. Universidade Federal do Paraná.

Ferreira, V. G., Zhang, Y. and De Freitas, S. R. C. 2013. Validation of GOCE gravity field models using GPS-leveling data and EGM08: A case study in Brazil. Journal of Geodetic Science, 3(3). doi: 10.2478/jogs-2013-0027

IBGE, 2017. Banco de Dados Geodésicos - BDG. Available at: <http://www.bdg.ibge.gov.br/appbdg/>. [Accessed 30 August 2017].

Luz, R. T. 2008. Estratégias para modernização da componente vertical do Sistema Geodésico Brasileiro e sua integração ao SIRGAS. PhD. Universidade Federal do Paraná.

Mäkinen, J. and Ihde, J., 2006. The permanent tide in height systems. In: Proceedings of the IAG/FIG Symposium "Geodetic Reference Frames" GRF2006. Munich, Germany, 9-14 October 2017.

Moreira, R. M. 2015. Conexão de Sistemas Verticais de Referência Locais ao Sistema Geodésico Brasileiro com base em um Sistema Vertical de Referência Global. PhD. Universidade Federal do Paraná.

Mueller, I. I. 1985. Reference Coordinate Systems and Frames: Concepts and realization. Journal of Geodesy, 59(2), 181-188. doi: 10.1007/BF02520609

Nicacio, E. L. 2016. SPGG - Single-Point GEM (Global Earth Models) Generator - v 2.0. Available at:<http://www.cienciasgeodesicas.ufpr.br/spgg/>. [Accessed 30 August 2017].

Nicacio, E. L. and Dalazoana, R. 2016. Análisis de extractos de Modelos Globales del Geopotencial generados punto a punto a partir de una aplicación standalone. In: SIRGAS 2016 Symposium. Quito, Ecuador, 16-18 November 2016.

Nicacio, E. L. 2017. Alternativa para determinação de altitudes normais-ortométricas na Amazônia Legal Brasileira. MSc. Universidade Federal do Paraná.

Nicacio, E. L. and Dalazoana, R. 2017. Evaluación de Modelos Globales del Geopotencial combinados modernos en el territorio brasileño. In: SIRGAS 2017 Symposium. Mendoza, Argentina, 27-30 November 2017.

Pail, R. et al. 2016. The Experimental Gravity Field Model XGM2016. In: 1st Joint Comission 2 and International Symposium on Gravity, Geoid and Height Systems 2016. Thessaloniki, Grécia, 19-23 September 2016.

Sánchez, L. 2016. Sistemas de referencia vertical. In: Taller SIRGAS en Sistemas Verticales de Referencia 2016. Quito, Ecuador, 21-25 November 2016.

Seeber, G. 2003. Satellite Geodesy: foundations, methods and applications. Berlin, New York: Walter de Gruyter. doi: 10.1515/9783110200089

Tenzer, R., Vatrt, V., Abdalla, A. and Dayoub, N. 2011. Assessment of the LVD offsets for the normal-orthometric heights and different permanent tide systems - a case study of New Zealand. Applied Geomatics, 3(1), 1-8. doi: 10.1007/s12518-010-0038-5 